\title{
Effect of levetiracetam drug on antioxidant and liver enzymes in epileptic patients: case-control study
}

\author{
Atena Mahdavi ${ }^{1}$, Amirmansour Alavi Naeini ${ }^{1}$, Mohammadreza Najafi ${ }^{2}$, Mohammadreza \\ Maracy $^{3}$, Mohammadreza Aghaye Ghazvini ${ }^{4}$
}

1. Department of Community Nutrition, School of Nutrition and Food Sciences, Isfahan University of Medical Sciences, Isfahan, Iran

2. Department of Neurology, School of Medicine, Isfahan University of Medical Science, Isfahan, Iran

3. Department of Epidemiology and Biostatistics, School of Health, Isfahan University of Medical Sciences, Isfahan, Iran

4. Isfahan Center of Health Research, National Institute of Health Research, Isfahan, Iran

\begin{abstract}
:
Background: There is a limited amount of data regarding levetiracetam (LEV), an antiepileptic drug.

Objective: This study was conducted to assess the effect of LEV on antioxidant status and liver enzymes.

Method: In this case-control study, 33 epileptic patients under treatment with LEV for at least 6 months were compared with 35 healthy subjects. We measured serum total antioxidant capacity (TAC), salivary superoxide dismutase (SOD), alanine aminoteransferase (ALT), and aspartate aminoteransferase (AST) levels in both groups. Dietary intakes were collected using a Food Frequency Questionnaire (FFQ).

Result: The level of TAC in the healthy subjects was significantly higher than it was in the patients $(\mathrm{P}=0.02)$, but the mean of ALT ( $\mathrm{P}=0.02)$ and AST $(\mathrm{P}=0.03)$ was significantly higher in the patients in comparison with the controls. Mean salivary SOD showed no difference between the two groups. In the patients, the duration of drug use was inversely correlated with serum TAC $(\mathrm{p}=0.04)$ and had a direct correlation with ALT $(\mathrm{p}=0.01)$ and AST $(\mathrm{p}=0.03$.$) .$

Conclusion: The results of our study indicated that LEV increased liver enzymes Also, treatment with this drug did not improve oxidative stress, but this could be due to the different in the dietary antioxidant intake. Routine screening of the liver and antioxidant enzymes in patients with chronic use of LEV is recommended.

Keywords: levetiracetam, antioxidant, liver enzymes, epilepsy

DOI: https://doi.org/10.4314/ahs.v20i2.55

Cite as: Mahdavi A, Naeini AA, Najafi M, Maracy M, Ghazvini MA. Effect of levetiracetam drug on antioxidant and liver ensymes in epileptic patients: case-control study. Afri Health Sci. 2020; 20(2): 984-990. https:// doi.org/10.4314/ abs.v20i2.55
\end{abstract}

\section{Introduction}

Epilepsy is a chronic brain disorder that affects people around the world. It is diagnosed by recurrent seizures that can affect a part of the body (partial) or the entire body (generalized), and is occasionally accompanied with loss of consciousness or control of the bladder and bowels. Recently, epilepsy prevalence was estimated at 5 to 10 per 1000 persons. It is reported that at least 100 million people worldwide will present with epilepsy ${ }^{1}$. The prevalence of epilepsy is $5 \%$ in $\operatorname{Iran}^{2}$. Seizure episodes result from dysfunction in the transport

\section{Corresponding author: \\ Amirmansour Alavi Naeini, \\ Department of Community Nutrition, School of Nutrition and Food Sciences, Isfahan University of Medical Sciences, Isfahan, Iran. \\ Email: am.alavi@nutr.mui.ac.ir}

or channel structure of the ion in the neuronal membrane $e^{3-5}$. Furthermore, impaired antioxidant defense mechanisms and increased lipid per oxidation also have a role in its pathogenesis ${ }^{6-8}$.

Oxidative stress is the result of an imbalance between the antioxidant defense system in the body and free radical production. The superoxide anion(O2-), hydrogen peroxide $(\mathrm{H} 2 \mathrm{O} 2)$, and hydroxyl radical $(\mathrm{OH})$ are active oxygen species which cause peroxidation of cell lipids ${ }^{9,10}$. The antioxidant defense system includes enzymatic (glocuse-6-phosphate dehydrogenate, glutathione peroxides, glutathione reductase, catalase, and superoxide dismutase) and non-enzymatic (vitamin E, glutathione, thiol and Uric acid) parts ${ }^{11,12}$. Although the presence of the antioxidant defense system resists the oxidative damage created by ROS, this damage may threaten the life of a person ${ }^{13}$. In this study we measured the serum TAC level and salivary SOD. SOD is 
a intracellular antioxidant enzyme that converts radical superoxide into a less toxic substance called hydrogen peroxide; catalase breaks the hydrogen peroxide enzyme $^{14}$. Another biomarker is TAC which measures the antioxidant power of bodily fluids ${ }^{15}$.

Aspartate aminotransferase (AST) and alanine aminoteransferase (ALT) are intracellular enzymes which are located in cytosol and mitochondria. ALT is more associated with the liver, while AST is an intracellular enzyme that is found in the liver, heart, skeletal muscles, kidneys, brain and erythrocytes ${ }^{16,17}$. Epilepsy control is dependent on the use of antiepileptic drugs (AEDs), which have side effects. Recently, new drugs that have the least side effects and least drug-drug interactions have been prescribed. Levetiracetam (LEV) is a new antiepileptic agent for controlling partial-onset seizures in adults and differs from old antiepileptic drugs due to its pharmacological properties and mechanisms of action ${ }^{18}$. The normal dosage of LEV in children and adults is $30-60 \mathrm{mg} / \mathrm{kg}$ day ${ }^{19}$. There are few studies reporting the effect of the second-generation antiepileptic drug. Therefore, we conducted this study to evaluate the antioxidant status and liver enzymes in patients with epilepsy treated with LEV.

\section{Material and methods}

Patients were selected from the Masih Epileptic Research Association and from among the patients of neuroscience physicians and treatment centers. The study was approved by Isfahan University of Medical Science's Ethics Committee (Ethical code: IR.MUI. REC.7395.3.688). A written consent form was taken from both patient and control group participants. Patients were diagnosed by CT brain scan and electroencephalography ,according to the International League Against Epilepsy (ILAE) ${ }^{20}$.

This case-control study was conducted on 33 epileptic patients (21 females and 12 males) who had been treated with LEV monotherapy, and were affected with generalized or focal epileptic seizures and 35 homogeneous individuals in terms of age and sex (21 females and 14 males) without epilepsy. The inclusion criteria were: 1- aged between 18-60 years; 2 - having had at least six months of LEV monotherapy; 3- confirmed diagnosis of epilepsy by a neurologist. The exclusion criteria of the study were: 1 - being a patient with any disease other than epilepsy and taking any other medications such as drugs causing elevation of liver enzymes (e.g. antibiotics, anti-rheumatic drugs, statins and nonsteroidal anti-inflammatory drugs); 2- addiction to alcohol and smoking; 3-having been affected by liver lesions or oth- er liver diseases; 4- being pregnant or breast-feeding; 5taking supplements of antioxidant; 6- being vegetarian; 7- having a ketogenic diet.

The required information from the participants, including demographic information, was obtained through a devised questionnaire. Nutrient intake was also determined using the Food Frequency Questionnaire (FFQ) and evaluated; the validity and reliability indices of the questionnaire were calculated.

\section{Sampling}

A $5 \mathrm{~mL}$ blood sample was taken from fasting participants and centrifuged for $10 \mathrm{~min}$. at $6000 \mathrm{rpm}$. Serum sections were separated by centrifugation and stored at $-20{ }^{\circ} \mathrm{C}$ until biochemical analysis was carried out.

\section{TAC serum}

The antioxidant ability of plasma was measured using the Rris et al method ${ }^{21}$. In this method, the reduction potential of ion-ferric to low $\mathrm{PH}$ depletion results in the production of the ferrotri-peridyltarine color spectrum that can be measured by absorption changes at $593 \mathrm{~nm}$.

\section{ALT, AST}

Amylase was measured using an enzyme commercial kit from Pars Tesh (Iran). In this method, the substrate contained in the kit is broken down by various alpha amylase units, which later become hydrolyzed by glucosidase and result in the production of paranitrofenol with a wavelength of 405 .

\section{Salivary SOD}

Superoxide dismutase was measured using a ZellBio $\mathrm{GmbH}$ (Germany) enzyme kit. In this method, anion superoxide is converted by enzymatic reaction to hydrogen peroxide and oxygen; the former eventually produces a colored composition whose light absorption is measured at $420 \mathrm{~nm}$.

\section{Statistical analysis}

Normal distribution was checked using the Kolmogorov Smirnov Test. The Independent samples t-test was used to compare quantitative variables between the cases and the controls. In the case of non-normal distributed variables, the Mann-Whitney test was applied. The Chi-square test was done to compare qualitative variables between the two groups. The Spearman correlation coefficient was used to show the relationship between the variables. SPSS (Ver. 22) software was used to analyze the data; $\mathrm{p}$ values less than 0.05 were considered statistically significant.

African Health Sciences Vol 20 Issue 2, June, 2020 


\section{Result}

Distribution of Demographic and Basic clinical characteristics in two groups is displayed in Table 1. The mean age in the patients was $30.2 \pm 11.7$ and in the control group $29.8 \pm 11.4$ years. The Independent samples t-test showed no significant difference between the two groups $(\mathrm{P}=0.90)$. The Chi-square test showed that there was no significant difference in the frequency distribution of gender between the two groups $(\mathrm{P}=0.76)$. The Mann-Whitney test showed that the level of education was similar in the two groups $(\mathrm{P}=0.57)$. There was no significantly difference between the two groups in terms of BMI.

Table 1: Distribution of Demographic and Basic clinical characteristics in two groups

\begin{tabular}{|c|c|c|c|c|}
\hline \multirow[t]{2}{*}{ Variable } & & & Healthy group & P-value \\
\hline & & $\mathrm{n}=\mathbf{3 3}$ & $n=35$ & \\
\hline \multirow[t]{3}{*}{ Gender N (\%) } & Male & $12(36.4)$ & $14(40)$ & \\
\hline & female & $21(63.6)$ & $21(60)$ & 0.76 \\
\hline & Less than diploma & $8(24.2)$ & $7(20)$ & \\
\hline Education level & Diploma & $14(42.4)$ & $14(40)$ & 0.57 \\
\hline \multirow[t]{2}{*}{$\mathrm{N}(\%)$} & Bachelor & $10(30.3)$ & $13(37.1)$ & \\
\hline & Higher than bachelor & $1(3)$ & $1(2.9)$ & \\
\hline Age (Y) & mean \pm SD & $30.2 \pm 11.7$ & $29.9 \pm 11.4$ & 0.9 \\
\hline $\begin{array}{c}\text { Duration of } \\
\text { using the } \\
\text { medicine (year) }\end{array}$ & mean \pm SD & $2.24 \pm 2.21$ & - & - \\
\hline $\begin{array}{l}\text { Dosage of } \\
\text { medicine } \\
(\mathrm{mg} / \text { day) }\end{array}$ & mean \pm SD & $992.42 \pm 477.97$ & - & - \\
\hline $\mathrm{BMI}\left(\mathrm{kg} / \mathrm{m}^{2}\right)$ & mean $\pm \mathrm{SD}$ & $24.51 \pm 5.56$ & $25.3 \pm 4.34$ & 0.48 \\
\hline
\end{tabular}

An Independent t-test showed that the mean of vitamin C levels in the healthy participants was significantly higher than it was in the patients $(\mathrm{P}=0.02)$ but the mean of vitamin $\mathrm{E}(\mathrm{P}=0.92), \mathrm{Zn}(\mathrm{P}=0.35)$, selenium $(\mathrm{P}=0.22)$ and beta-carotene $(\mathrm{P}=0.92)$ was similar in the two groups (table 3 ).

An Independent t-test showed that the serum TAC mean in the controls was significantly higher compared to the patients $(\mathrm{P}=0.02)$, but the mean of ALT $(\mathrm{P}=$ $0.02)$ and AST $(P=0.03)$ in the patients was significant- ly higher than the control group. The mean of salivary SOD was the same in the two groups $(\mathrm{P}=0.75)$ (table 2).

However, the Spearman correlation coefficient showed that in the patients, the duration of drug use was in reverse correlation with serum TAC $(r=-0.240, p=$ $0.04)$ and in direct correlation with $\operatorname{ALT}(\mathrm{r}=0.365, \mathrm{p}=$ $0.01)$ and AST $(r=0.283, p=0.03)$. There was no significant correlation between duration of drug use and salivary SOD $(\mathrm{r}=0.051, \mathrm{p}=0.39)$ (figure 1$)$. 
Table 2: the mean of salivary SOD, serum TAC, SGOT and SGPT in two groups

\begin{tabular}{|c|c|c|c|}
\hline \multirow[t]{2}{*}{ Variable } & Patients, $n=33$ & $\begin{array}{c}\text { Healthy group, } \\
\mathbf{n}=35\end{array}$ & \multirow[t]{2}{*}{ P-value } \\
\hline & mean $\pm \mathrm{SD}$ & mean $\pm \mathrm{SD}$ & \\
\hline salivary SOD(U/ml) & $31.7 \pm 8.5$ & $32.4 \pm 8.9$ & 0.75 \\
\hline serum TAC(mg/dl) & $15.8 \pm 5.2$ & $19 \pm 7.8$ & 0.02 \\
\hline AST(IU/L) & $27.5 \pm 18.9$ & $21.02 \pm 4.9$ & 0.02 \\
\hline ALT(IU/L) & $25.1 \pm 14.9$ & $19.7 \pm 7.2$ & 0.03 \\
\hline \multicolumn{4}{|c|}{$\begin{array}{l}\text { AST: Aspartate Aminotransferase, ALT: Alanine Aminotransferase, } \\
\text { dismutase, TAC: Total antioxidant capacity }\end{array}$} \\
\hline \multicolumn{4}{|c|}{$\begin{array}{l}\text { Table 3: The mean of vitamin } C \text {, vitamin } E \text {, zinc, selenium and beta-carotene in } \\
\text { two groups }\end{array}$} \\
\hline \multirow[t]{2}{*}{ variable } & Patients,$n=33$ & $\begin{array}{c}\text { Healthy group, } \\
\mathbf{n}=35 \\
\end{array}$ & \multirow[t]{2}{*}{ P-value } \\
\hline & mean \pm SD & mean \pm SD & \\
\hline vitamin C (mg) & $70.5 \pm 35.6$ & $94.9 \pm 49.9$ & 0.02 \\
\hline vitamin E (mg) & $8.1 \pm 5.2$ & $8 \pm 5.8$ & 0.92 \\
\hline Zinc (mg) & $6.70 \pm 2.48$ & $6.75 \pm 2.38$ & 0.35 \\
\hline selenium (mg) & $0.027 \pm 0.018$ & $0.035 \pm 0.030$ & 0.22 \\
\hline Betacarotene $(\mu \mathrm{g})$ & $724.5 \pm 407.8$ & $737.3 \pm 582.9$ & 0.92 \\
\hline
\end{tabular}

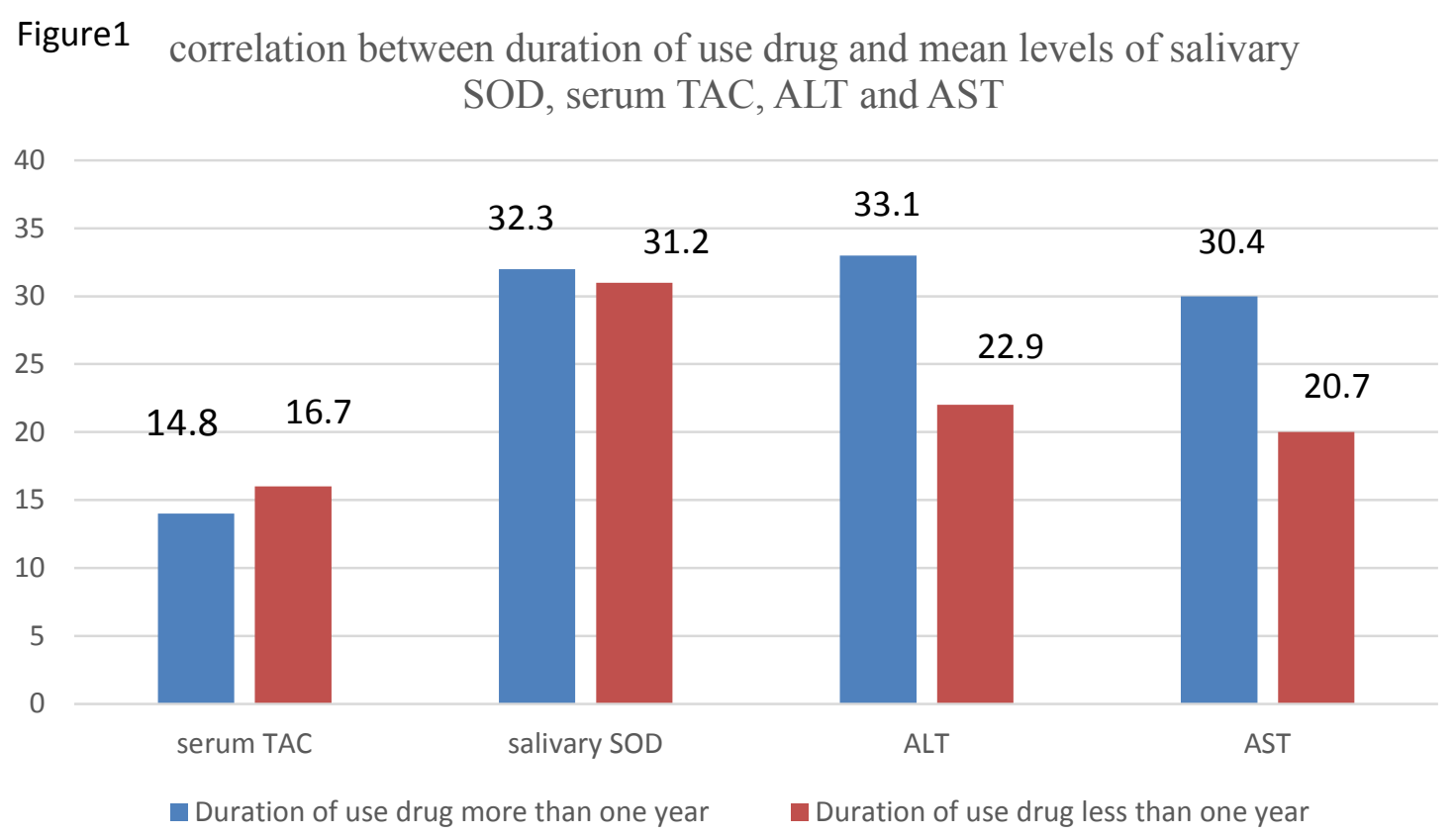




\section{Discussion}

This study was conducted in 33 patients with epilepsy. These patients had used LEV at least 6 months before entering the study. The serum TAC level was lower in the patients compared to the control subjects, salivary SOD did not differ between the two groups, and the level of liver enzymes was higher in the patients.

The antioxidant intake measured by the FFQ questionnaire showed that vitamin $C$ intake was significantly higher in the control subjects than the patients, but no significant difference was found between other antioxidant intakes. This may indicate that because the former group consumed more fruits and vegetables and had a healthier diet, they had a higher serum TAC level than the latter; thus, diet as an important factor can affect antioxidant serum levels in the body.

Another important factor to be considered is the relationship between the duration of medicine use and antioxidant level in the body and in the liver enzymes; in fact, patients who use AEDs on a long-term basis have higher levels of ALT, AST and a lower antioxidant level. Thus, treatment with LEV as an AED did not improve oxidative stress parameters. With consumption of higher quantities of oxygen, there is more vulnerability to oxidative stress. This plays a significant role in the pathogenesis of a number of brain disorders, including epilepsy, migraine, and stroke ${ }^{22}$. In addition, defective ion transport, inhibitory excitatory mechanisms, and lipid per oxidation due to increase in free radicals or reduction of antioxidant defense system activity may take some forms of epilepsy and increase the recurrences of seizures ${ }^{23-26}$. Some studies have reported that AEDs have antioxidant effect, one finding also shows the effectiveness of using benzodiazepine in decreasing the frequency of seizures ${ }^{27}$.

Bolagir E et al reported that AEDs such as oxacarbamazepine as a new-AED have antioxidant effects 28 - Another study showed that epileptic children under therapeutic doses of levetiracetam had significantly increased levels of MDA and 8-OHdG, which is defensive for oxidative damage ${ }^{29}$. Baysal $\mathrm{M}$ et al also showed that SOD activity was increased in male patients after LEV therapy compared to placebo. The authors have recommended that LEV therapy may improve oxidative stress ${ }^{30}$. But some studies, e.g. Keshin Guler S et al, have also shown that antiepileptic treatment does not affect oxidative stress parameters. In contradiction to our findings, a study conducted on the properties of LEV and clonazpam in mice demonstrated the role of these new drugs in coping with oxidative stress ${ }^{31}$; it can be said that LEV is a new drug that is distinguished from other drugs due to its various characteristics including its medicinal properties and mechanism of action, although its precise mechanism is still unclear ${ }^{32}$. It has been shown that LEV binds to the synaptic protein $2 \mathrm{~A}$. By binding to this protein vesicle, LEV acts as an exocytose modulator which prevents pre-synaptic neurotransmitter release; therefore, LEV acts as a protective antioxidant -induced neurotoxicity in several models of seizures ${ }^{33,34}$. The role of free radicals in seizures originates from the use of administered antioxidants such as vitamin $\mathrm{C}$ to preserve the brain against seizure caused by oxidative stress ${ }^{35}$.

Fewer studies have reported that treatment with AEDs may have an antioxidant effect ${ }^{36}$. Increasing the free radicals and reducing the antioxidant defense system can cause seizures as well as recurrence of seizures. Some AEDs metabolize and produce metabolites that cause covalent binding to proteins and other biomolecules hence eliciting system toxicity ${ }^{37}$.

CYP P450 is responsible for the biotransformation of several drugs, and iso- enzymes are membrane proteins which are in the endoplasmic reticulum of several tissues. CYP3A4 and CYP3A5 are isomers in CYP450 and interfere with some drugs such as AED ${ }^{38,39}$. CYP3A4 has been found in large numbers in the liver and intestine so it is responsible for the metabolism of many clinically used drugs ${ }^{39}$.

Cytochrome P450 isomers are stimulated by AEDs especially classical AEDs such as carbamazepine, benzodiazepine, valproic acid, Phenobarbital and phenytoin. Some studies have suggested that chronic liver enzymes and transient increase in ALT and AST during chronic treatment with some drugs including phenytoin not only cause liver toxicity, but also induce the enzymes ${ }^{40}$. During the onset of AEDs, hepatic enzymes increase due to enzyme induction, as in the case of our study patients who had received AED for at least 6 months, but over time, liver tests may appear normal due to adaptation in the liver. Thus, increase of ALT and AST in our patients had no sign of liver damage and hepatotoxicity. This shows that increase of these enzymes does not cause liver problems.

One of the limitations in our study was the small number of patients. Also, we had no information about the status of the patients before LEV consumption. Thus, we could not compare the factors with or without treatment by anti-epilepsy medicines. Finally, we did not observe the long-term effects of LEV. The strong point of our study was the investigation of the patients' diet, 
which was done using the Food Frequency Questionnaire (FFQ) and showed to be effective on the significance or insignificance of the serum factors. It should be added that we investigated the effect of levetiracetam as a monotherapy drug on antioxidant status and liver enzymes only.

The results of our study indicate that LEV is a drug which has little effect on liver metabolism, but increases the level of liver enzymes while decreasing the overall antioxidant capacity. This can be due to the duration of at least 6 months; perhaps over time, the body would adapt to these conditions and normalize the measured factors. Also, based on the mechanisms described, that LEV has a protective effect against oxidative stress and decrease in serum TAC level in patients compared with healthy subjects can be due to different diets that patients had in terms of using less antioxidant containing foods. However, routine screening of the liver and antioxidant enzymes in patients with chronic use of the $\mathrm{LEV}$ drug is recommended.

In future studies, findings with a larger sample size and a longer study period are recommended in these patients.

\section{Conflicts of interest and source of funding None.}

\section{Abbreviations}

AEDs: Anti Epileptic Drugs, ALT: Alanine AminoTeransferase, AST: Aspartate AminoTeransferase, FFQ: Food Frequency Questionnaire, ILAE: International League Against Epilepsy, LEV: levetiracetam, SOD: Salivary Superoxide Dismutase, TAC: Total Antioxidant Capacity

\section{References}

1. Fontes LP, Fontes MP, Jiménez PQ, Pérez JM, Iriarte MM. Comparative case-control study of homocysteine, vitamin B12, and folic acid levels in patients with epilepsy. Neurología (English Edition). 2017;32(7):440-5.

2. Sayehmiri K, Tavan H, Sayehmiri F, Mohammadi I, Carson KV. Prevalence of epilepsy in Iran: a meta-analysis and systematic review. Iranian Journal of Child Neurology. 2014;8(4):9.

3. Dichter MA. Models of epileptogenesis in adult animals available for antiepileptogenesis drug screening. Epilepsy Research. 2006;68(1):31-5.

4. Pitkänen A, Kharatishvili I, Karhunen H, Lukasiuk K, Immonen R, Nairismägi J, et al. Epileptogenesis in experimental models. Epilepsia. 2007;48(s2):13-20.
5. Najm I, Ying Z, Janigro D. Mechanisms of epileptogenesis. Neurologic Clinics. 2001;19(2):237-50.

6. Rauca C, Zerbe R, Jantze H. Formation of free hydroxyl radicals after pentylenetetrazol-induced seizure and kindling. Brain Research. 1999;847(2):347-51.

7. Menon B, Ramalingam K, Kumar RV. Oxidative stress in patients with epilepsy is independent of antiepileptic drugs. Seizure-European Journal of Epilepsy. 2012;21(10):780-4.

8. Ercegovac M, Jovic N, Simic T, Beslac-Bumbasirevic L, Sokic D, Djukic T, et al. Byproducts of protein, lipid and DNA oxidative damage and antioxidant enzyme activities in seizure. Seizure-European Journal of Epilepsy. 2010;19(4):205-10.

9. Valko M, Leibfritz D, Moncol J, Cronin MT, Mazur M, Telser J. Free radicals and antioxidants in normal physiological functions and human disease. The International Journal of Biochemistry \& Cell Biology. 2007;39(1):4484.

10. Pisoschi AM, Pop A. The role of antioxidants in the chemistry of oxidative stress: A review. European Journal of Medicinal Chemistry. 2015;97:55-74.

11. ÇÖMELEKOĞLU Ü, Mazmanci B, Arpaci A. Erythrocyte Superoxide Dismutase and Catalase Activities in Agriculture Workers Who Have Been Chronically Exposed to Pesticides. Turkish Journal of Biology. 2000;24(3):483-8.

12. Menon B, Ramalingam K, Kumar RV. Low plasma antioxidant status in patients with epilepsy and the role of antiepileptic drugs on oxidative stress. $A n$ nals of Indian Academy of Neurology. 2014;17(4):398.

13. Cardenas-Rodriguez N, Huerta-Gertrudis B, Rivera-Espinosa L, Montesinos-Correa H, Bandala C, Carmona-Aparicio L, et al. Role of oxidative stress in refractory epilepsy: evidence in patients and experimental models. International Journal of Molecular Sciences. 2013;14(1):1455-76.

14. Guler SK, Aytac B, Durak ZE, Cokal BG, Gunes $\mathrm{N}$, Durak I, et al. Antioxidative-oxidative balance in epilepsy patients on antiepileptic therapy: a prospective case-control study. Neurological Sciences. 2016;37(5):7637.

15. Peluso I, Raguzzini A. Salivary and urinary total antioxidant capacity as biomarkers of oxidative stress in humans. Pathology Research International. 2016;2016.

16. Chang R, Chou M-C, Hung L-Y, Wang M-E, Hsu M-C, Chiu C-H. Study of valproic acid-enhanced hepatocyte steatosis. BioMed Research International. 2016;2016.

17. Serdaroglu F, Koca T, Dereci S, Akçam M. The etiology of hypertransaminasemia in Turkish children. Bosnian Journal of Basic Medical Sciences. 2016;16(2):151. 
18. Radtke RA. Pharmacokinetics of levetiracetam. Epilepsia. 2001;42(s4):24-7.

19. Fürwentsches A, Bussmann C, Ramantani G, Ebinger F, Philippi H, Pöschl J, et al. Levetiracetam in the treatment of neonatal seizures: a pilot study. Seizure. 2010;19(3):185-9.

20. Engel J. A proposed diagnostic scheme for people with epileptic seizures and with epilepsy: report of the ILAE Task Force on Classification and Terminology. Epilepsia. 2001;42(6):796-803.

21. Benzie IF, Strain JJ. The ferric reducing ability of plasma (FRAP) as a measure of "antioxidant power": the FRAP assay. Analytical Biochemistry. 1996;239(1):706.

22. Jesberger JA, Richardson JS. Oxygen free radicals and brain dysfunction. International Journal of Neuroscience. 1991;57(1-2):1-17.

23. Yiiksel A, Cengiz M, Seven M, Ulutin T. Erythrocyte glutathione, glutathione peroxidase, superoxide dismutase and serum lipid peroxidation in epileptic children with valproate and carbamazepine monotherapy. Journal of Basic and Clinical Physiology and Pharmacology. 2000;11(1):73-81.

24. Niketić V, Ristić S, Saicić Z, Spasić M, Buzadzić B, Stojković M. Activities of antioxidant enzymes and formation of the glutathione adduct of hemoglobin (Hb ASSG) in epileptic patients with long-term antiepileptic therapy. Farmaco (Societa chimica italiana: 1989). 1995;50(11):811-3.

25. Hurd R, editor Zinc binding by valproic acid. Neuroscience Abstr, 1981.

26. Abbott LC, Nejad HH, Bottje WG, Hassan AS. Glutathione levels in specific brain regions of genetically epileptic (tg/tg) mice. Brain Research Bulletin. 1990;25(4):629-31.

27. Wolf P. Acute administration of benzodiazepines as part of treatment strategies for epilepsy. CNS Neuroscience \& Therapeutics. 2011;17(4):214-20.

28. Bolayir E, Celik K, Tas A, Topaktas S, Bakir S. The effects of oxcarbazepine on oxidative stress in epileptic patients. Methods and Findings in Experimental and Clinical Pharmacology. 2004;26(5):345-8.

29. Haznedar P, Doğan Ö, Albayrak P, Tunçer GÖ, Teber S, Deda G, et al. Effects of levetiracetam and valproic acid treatment on liver function tests, plasma free carnitine and lipid peroxidation in childhood epilepsies. Epilepsy Research. 2019;153:7-13.

30. Baysal M, Ilgin S, Kilic G, Kilic V, Ucarcan S,
Atli O. Reproductive toxicity after levetiracetam administration in male rats: evidence for role of hormonal status and oxidative stress. PloS One. 2017;12(4):e0175990. 31. de Albuquerque Oliveira A, Linhares MI, Chaves Filho AJ, Maia e, Rios ERV, de Carvalho Lima $\mathrm{CN}$, et al. Antioxidant properties of antiepileptic drugs levetiracetam and clonazepam in mice brain after in vitro-induced oxidative stress. African Journal of Pharmacy and Pharmacology. 2016;10(14):278-88.

32. Gibbs JE, Walker MC, Cock HR. Levetiracetam: antiepileptic properties and protective effects on mitochondrial dysfunction in experimental status epilepticus. Epilepsia. 2006;47(3):469-78.

33. Rigo JM, Hans G, Nguyen L, Rocher V, Belachew S, Malgrange B, et al. The anti-epileptic drug levetiracetam reverses the inhibition by negative allosteric modulators of neuronal GABA-and glycine-gated currents. British Journal of Pharmacology. 2002;136(5):659-72. 34. Oliveira A, Almeida J, Freitas R, Nascimento V, Aguiar L, Júnior $\mathrm{H}$, et al. Effects of levetiracetam in lipid peroxidation level, nitrite-nitrate formation and antioxidant enzymatic activity in mice brain after pilocarpine-induced seizures. Cellular and Molecular Neurobiology. 2007;27(3):395-406.

35. Barros D, Xavier S, Barbosa C, Silva R, Freitas $\mathrm{R}$, Maia $\mathrm{F}$, et al. Effects of the vitamin $\mathrm{E}$ in catalase activities in hippocampus after status epilepticus induced by pilocarpine in Wistar rats. Neuroscience Letters. 2007;416(3):227-30.

36. Nemade ST, Melinkeri R. Effect of antiepileptic drugs on antioxidant status in epilepsy. Curr Neurobiol. 2010;1(2):109-12.

37. Hamed SA, Abdellah MM, El-Melegy N. Blood levels of trace elements, electrolytes, and oxidative stress/antioxidant systems in epileptic patients. Journal of Pharmacological Sciences. 2004;96(4):465-73.

38. Fan H-C, Lee H-S, Chang K-P, Lee Y-Y, Lai H-C, Hung P-L, et al. The impact of anti-epileptic drugs on growth and bone metabolism. International Journal of Molecular Sciences. 2016;17(8):1242.

39. Ndrepepa G, Kastrati A. Gamma-glutamyl transferase and cardiovascular disease. Annals of Translational Medicine. 2016;4(24).

40. Hadzagic-Catibusic F, Hasanbegovic E, Melunovic M, Zubcevic S, Uzicanin S. Effects of Carbamazepine and Valproate on Serum Aspartate Aminotransferase, Alanine Aminotransferase and Gamma-Glutamyltransferase in Children. Medical Archives. 2017;71(4):239. 